\title{
Algumas contribuições teóricas do referencial psicanalítico para as pesquisas sobre organizações
}

\author{
Ana Magnólia Bezerra Mendes \\ Universidade de Brasília
}

\begin{abstract}
Resumo
O texto tem por objetivo fazer uma reflexão sobre alguns aspectos epistemológicos e metodológicos do uso do referencial psicanalítico em pesquisas sobre organizações. A discussão busca clarificar as tensões da relação entre essas disciplinas, demonstrando que é possível uma integração teórica. A idéia de referência é a construção de diálogos e de complementariedades na apreensão de determinados fenômenos, tendo como foco de análise as contribuições da Psicanálise para o estudo das relações simbólicas indivíduo-trabalho-organização como um dos caminhos para desvelar a dinâmica organizacional. São discutidas estratégias metodológicas como observações, análise de documentos, escalas e entrevistas semi-estruturadas coletivas e individuais, tendo como pressuposto o modo de escuta dos fenômenos organizacionais, a forma de analisar o dado, de interpretar e de construir o conhecimento. Ainda é apresentada uma breve discussão de algumas pesquisas empíricas que vem sendo desenvolvidas nas organizações com base teórica no referencial psicanalítico.
\end{abstract}

Palavras-chave: Psicanálise, Metodologia, Organizações

\begin{abstract}
Theoretical contributions of psychoanalysis to organizational research. The paper's objective is to make a reflection about epystemological and methodological issues in the use of psychoanalysis in organizational research. The discussion aims to clarify the relationship between those disciplines demonstrating that it is possible to make a theoretical integration. The idea of this paper is to construct dialogues and to complement the specific phenomena apprehension, having as the focus of analysis the psychoanalysis contributions for the individual-work-organization symbolic relationships study as a way to see organizational dynamics. It discusses methodological strategies such as observations, document analysis, scales and semi structured collective and individual interview. We propose a specific approach to work with organizational phenomena, to analyze the data, to interpret and to build the knowledge. It is still presented a brief discussion about some empiric researches that have been developed with organizations with psychoanalysis as a theoretical support.
\end{abstract}

Key words: Psychoanalysis, Methodology, Organizations

$\mathrm{B}$ uscam-se discutir nesse artigo algumas contribuições teóricas da Psicanálise, mais especificamente, conceitos desenvolvidos por Freud, para as pesquisas com organizações. Não é intenção um aprofundamento na Psicanálise, mas tomar de empréstimo alguns conceitos que contribuem para uma proposta de um outro modo de escutar os fenômenos organizacionais, enfocando o entendimento dos aspectos dinâmicos que se integram ao entendimento do funcionamento, dos processos e dos comportamentos organizacionais.

Para dar conta desses objetivos, divide-se o texto em três partes: reflexões sobre questões epistemológicas, ques- 
tões metodológicas e uma breve discussão de algumas pesquisas que vêm sendo realizadas com base em conceitos psicanalíticos.

\section{Reflexões sobre alguns aspectos epistemológicos}

Quando se fala em Psicanálise não se pode esquecer sua história, as influências que a determinaram e as circunstâncias nas quais foi criada. Para Freud (1913/1996; 1914/ 1996), a Psicanálise é um método de pesquisa das neuroses, especificamente um método de tratamento, mas com seu desenvolvimento houve uma extensão para outros campos. A descoberta da sexualidade infantil abre uma perspectiva para a Psicanálise ser um modo de encarar os processos psíquicos que podem ser medidos pelo valor do seu efeito sobre elementos afetivos, sendo essa a especificidade para a mudança de foco da visão da vida psíquica.

Do ponto de vista epistemológico, tomar de empréstimo da Psicanálise alguns conceitos para entender a dinâmica organizacional significa enfocar os processos intrapsíquicos e o inconsciente como fundamentais na determinação dessa dinâmica, que envolve relações simbólicas indivíduo-organização. É também, considerar o não-dito como um referente para interpretar os dados e entender os fenômenos organizacionais.

Para Celes e Bucher (1984), a marca em Freud é a dúvida do que está lá, além da consciência, além do manifesto. Essa dúvida tem de estar na base das pesquisas que utilizam os referenciais psicanalíticos. O que está por trás dos comportamentos? Essa é a pergunta. É necessário primeiro investigar o próprio comportamento manifesto, pois ele constitui um caminho para ser desvelado o comportamento latente.

Assim sendo, o dado empírico em si mesmo é o ponto de partida para a dúvida, sendo na interpretação desta dúvida que se instala uma epistemologia construtivista-subjetiva e uma metodologia abrangente e lógica nas suas próprias especificidades.

Nesta perspectiva caberia a questão, que traz controvérsias ao serem julgados modos de fazer ciência como erros epistemológicos de como combinar ciência empírica com metafísica, lugar dado a Psicanálise pelas ciências naturais. Diríamos que é necessário rever os critérios de cientificidade, criando-se uma epistemologia diferencial, que abarque uma integração entre o teórico e o empírico numa perspectiva de questionar como o conhecimento é desenvolvido. Assim, encontra-se na interpretação dos dados a forma de construir o conhecimento, sendo considerados para esta interpretação, tanto os conceitos desenvolvidos em determinado campo de estudo como os pressupostos epistemológicos que os sustentam.

Ao usar o referencial psicanalítico, busca-se interpretar os fenômenos organizacionais a partir de uma rede de signi- ficados, considerando a organização como uma entidade psicológica. Não se negligencia suas formas de funcionamento e processos, e como uma entidade não se teria outro caminho para desvelá-la enquanto "sujeito de si próprio" senão pela captura dessa rede de significados. A partir da análise do manifesto, com uso de instrumentos variados, pode ser perseguido o significado latente que vai dar um sentido a um contexto específico num determinado momento da vida organizacional.

Assim sendo, usar o referencial psicanalítico nas pesquisas sobre organizações significa tomar seus conceitos de empréstimo para entender um objeto: a relação simbólica indivíduo-trabalho-organização e a dinâmica em que esse objeto está inserido. Para tanto, busca-se a objetividade necessária à ciência, o que não significa a desconsideração da dúvida como lugar do inconsciente e a construção subjetiva do conhecimento a partir da interpretação do empírico.

A interpretação, então, assume lugar central nas pesquisas nas organizações com o referencial psicanalítico. Essa interpretação é uma forma de duvidar do que está posto. É necessário um exercício sistemático da dúvida para entender o significado do fenômeno, os motivos do pesquisador e do pesquisado para emitir esta ou aquela fala, resposta e/ou indícios, sendo a construção de uma rede de significados originada numa variedade de dados, o ponto de partida para entender a dinâmica organizacional.

Para Gabriel (1999), fazer pesquisa em organizações usando Psicanálise leva a particularidades epistemológicas do modo de construir o conhecimento. Uma primeira particularidade diz respeito à busca de insights, mais do que um volume uniforme e unidirecional de dados. Para o autor, a Psicanálise vai além da fenomenologia, da interação simbólica e do construtivismo social. A Psicanálise desconfia da verdade, da fala manifesta e adiciona as experiências do passado para explicar fenômenos atuais, não aceitando as evidências dos significados. A busca dessa verdade não é para desmenti-la no nível cognitivo, mas para engajar o seu sentido no nível do significado e do desejo, no nível que não é mentira cognitiva, mas verdade da gratificação do desejo.

Uma segunda particularidade é a existência da resistência dos participantes da pesquisa. Essa resistência deve ser apropriada pelos pesquisadores que, ao descobrirem seus objetivos e funcionamento, podem ter grandes chances de corroborar suas interpretações.

Nesse sentido, muito se tem a aprender com o diálogo entre as teorias organizacionais e a Psicanálise. De um lado, a Psicanálise precisa dos conceitos da teoria da burocracia, da cultura e do simbolismo organizacional, da emoção, da complexidade, do processo de trabalho, do controle, dos sistemas abertos, da aprendizagem gerencial e organizacional, dentre outros. De outro, a Psicanálise pode contribuir para 
as teorias organizacionais com a exploração do inconsciente, usando seus referenciais teóricos para modificar o já posto, procurando provar, testar, desenvolver e transcender alguns dos constructos já estudados pela Psicologia Organizacional tradicional, na tentativa de ampliar os insights sobre o fenômeno estudado.

\section{Questões metodológicas}

Para Gabriel (1999), as maiores dificuldades de fazer pesquisa nas organizações com esse referencial é que as teorias e conhecimento organizacionais têm bases muito variadas e sua aplicação é bastante específica, não sendo por isso, possível usar o mesmo critério e testes para acessá-las. As pesquisas em organizações com o referencial psicanalítico devem usar diferentes estratégias metodológicas devido à complexidade do que se busca investigar, bem como deve variar em função do objeto a ser estudado: o indivíduo, a organização ou a entidade abstrata, requerendo instrumentos específicos e coerentes com os procedimentos e análise a serem adotados.

Podem ser utilizadas como estratégias de coleta de dados observações, entrevistas, questionários e documentos. Cada uma destas estratégias aqui tratadas devem ser consideradas nas suas especificidades ao estarem ligadas a determinados objetos de investigação, que, no caso, estão fundamentadas por referenciais psicanalíticos e visam ao entendimento da dinâmica organizacional, como objeto último de interpretação.

A observação pressupõe o engajamento do pesquisador na organização e com seus membros. O objetivo é a busca constante de dicas e o sentido do que parece trivial. Envolve um processo ativo, de movimento do detalhe para o geral e uma redefinição do geral para o particular. Ainda, deve ser centrada nas questões e áreas que tenham valor para análises posteriores.

As observações podem ser de coisas materiais, do indivíduo e do comportamento dos grupos em interação. O material diz respeito à natureza e tamanho do edifício onde a organização funciona, às roupas dos indivíduos, ao lay out dos departamentos, ao estacionamento, entre outras categorias. Dos indivíduos e grupos é importante não só observar o que falam ou fazem, mas o como fazem e falam, como por exemplo, a entonação da voz, o uso de slogans e jargões, a linguagem corporal, a manifestação das emoções, os sinais de confiança e desconfiança.

As categorias de observação devem ser definidas a partir do objeto a ser investigado. Nem sempre são necessárias observações de todas as categorias recomendadas. Essa definição está atrelada às outras formas de coleta de dados, sendo a elas complementares. A eficácia das observações encontra-se no equilíbrio entre a busca de categorias a partir dos referenciais teóricos da pesquisa, sem, entretanto, prender os dados em grades predefinidas.

As entrevistas são consideradas por si só uma parte importante da relação interpessoal, como um momento de aprendizagem para o entrevistado. Segundo Cassel e Symom (1994), na entrevista o participante relata a concepção de indivíduo-organização dada pelos próprios indivíduos. Esse relato deve servir para formular novas hipóteses e alterar antigas como um progresso na pesquisa, permitindo a emergência de uma luz, um insight, que permite uma redefinição do que está sendo dito.

O momento da entrevista, segundo Assunção (1977), é um processo de ligação, de mutualidade, um elo perceptoideativo estabelecido pelos laços emocionais e processos imitativos e identificatórios. Na medida em que o entrevistado fala, o entrevistador vai limpando o que foi enfatizado versus o não-falado, o omitido versus o reprimido. $\mathrm{O}$ entrevistador chega ao imaginário através do simbólico, que é a linguagem. É difícil constatar na entrevista esse imaginário, que geralmente está associado a conteúdos de medo, ameaça e ansiedade. No contexto da entrevista fazem-se análises da estrutura dos seus componentes e observação das significações trazidas, identificando a relação do entrevistado com o entrevistador, para compreender o como o entrevistado faz suas trocas no passado e como elas se revelam e/ou atualizam agora no presente, na relação atual.

Para tal, a linguagem verbal e não-verbal é fundamental. Sem uma análise minuciosa dela não se pode fazer pesquisa com referencial psicanalítico, porque os elementos reveladores do latente serão encobertos pelos elementos falados e descritos no discurso manifesto. Não havendo espaço para dúvida, haverá um comprometimento da interpretação final dos resultados como o caminho mais apropriado para fazer pesquisa com Psicanálise.

A entrevista, para quem usa os referenciais da Psicanálise, é considerada, segundo Bleger (1991) e Mannoni (1981), uma relação intersubjetiva entre dois sujeitos com sua história de vida, conflitos e ambivalência, tendo em vista que os desejos infantis estão presentes no momento da entrevista, manifestando-se nos pedidos e querer do entrevistado. $\mathrm{O}$ inconsciente se faz presente na forma de desejos durante a realização da entrevista.

O mais importante na entrevista, em pesquisa com Psicanálise nas organizações, é estimular a fantasia do entrevistado. Segundo Gabriel (1999), perguntas podem ser feitas no intuito de trazer à tona conteúdos inconscientes, como exemplo: Isso realmente aconteceu? Por quê? Mais alguém viu? Quando? Onde?

Para se obter uma entrevista produtiva no referencial psicanalítico, é necessária uma grande habilidade de ouvir, deve-se estar livre para ouvir o que está fora de sua expecta- 
tiva. As hipóteses devem acompanhar as questões, as quais não devem seguir um roteiro ritualístico. É importante concentração e envolvimento emocional. Ao final da entrevista, o pesquisador deve se fazer estas perguntas: Por que não gostei dessa pessoa? O que me faz sentir desconforto com o que ela me disse? Por que, de repente, eu mudei de atitude num determinado ponto da entrevista? Como eu poderia ficar mais perto do cerne da questão? Por que este comentário ou palavra me mobilizou?

Os dados da entrevista devem ser combinados com informações fatuais da organização. Devem ser incluídos dados financeiros, incidentes importantes, dados demográficos e outras estatísticas.

Os questionários são menos usados, ainda que o anonimato seja um dos elementos importantes quando as pessoas não querem colaborar com a pesquisa. Perguntas abertas são mais recomendadas, como exemplo, relatar um incidente que causou raiva, alegria, embaraço ou tristeza no seu departamento. Também podem ser usadas técnicas de associação de palavras. O pesquisador diz uma palavra e o respondente diz o que aquela palavra o faz lembrar.

Um outro instrumento estruturado que pode ser utilizado é escalas de atitudes, as quais têm papel descritivo. Permitem uma descrição da situação geral da organização sob o ponto-de-vista da maioria dos seus membros. São importantes no sentido de mostrar a direção em que o fenômeno acontece na organização naquele momento e contexto organizacional, sendo de grande valia seus resultados para subsidiarem e corroborarem as entrevistas e as observações.

Os documentos são utilizados em pesquisa com referencial psicanalítico da mesma forma que os são para pesquisas com teorias organizacionais. A principal distinção encontra-se na análise, que deve pressupor um conteúdo latente que perpassa o manifesto, buscando entender as informações no contexto em que foram produzidas, ou seja, por quem, por que, para quem e com que intenção.

A combinação de diferentes técnicas de coleta e análise de dados permitem, segundo Cassel e Symon (1994), apreender a complexidade organizacional por envolver diversos atores de um processo que dá origem a uma dinâmica própria àquela organização.

A coleta de dados qualitativos é sensível o suficiente para permitir a análise do particular e o quantitativo, do geral, constituindo dessa forma, procedimentos nos quais estão envolvidos quais, como e por que ocorrem determinados fenômenos na organização, permitindo o desvelamento da sua dinâmica.

As estratégias de pesquisa e natureza do material coletado dependem da natureza do campo de investigação. No caso, para o pesquisador que usa o referencial psicanalítico, o mais importante é descobrir o significado inconsciente e o processo em que ele se insere, enfocando na fantasia uma das mais importantes unidade de análise. A fantasia representa a formação de compromisso entre inconsciente e consciente. Entretanto, isso não é suficiente. É preciso estabelecer a distância entre a fantasia e a realidade objetiva. A variedade de técnicas de coletas de dados favorece o acesso a dinâmica organizacional, não sendo privilegiada apenas um tipo de técnica, mas sim, um conjunto de estratégias metodológicas, sobretudo porque encontra-se na base dos dados empíricos, o ponto de partida para interpretação, que é uma das características essenciais para a pesquisa com o referencial psicanalítico.

Segundo Gabriel (1995), a interpretação é a arte, know how, tanto quanto a habilidade tácita do método científico. As interpretações específicas podem, ou não, serem aprovadas por critérios científicos convencionais. Podem ser originais, preceptivas, mas também incompletas, sem direção, fracas e erradas. Por isso, nem sempre são válidas todas as interpretações.

Para o autor, a validade está relacionada com quatro técnicas que podem corroborar uma interpretação e torná-la forte: a) a consistência interna, na qual a interpretação das partes é consistente com a interpretação geral; b) diferentes signos devem apontar para uma mesma direção, bem como diferentes mecanismos podem ser estabelecidos na direção dos mesmos resultados; c) deixar claro as evidências que podem servir para sua própria refutação; d) a interpretação tem um endereço certo. Explica-se como aconteceu e suplanta o menos forte para que o forte se sobressaia.

Finalmente, a interpretação como essência da pesquisa com o referencial psicanalítico, não deve ser submetida a regras, encontra-se a sua maior força na sua especificidade em relação a um conjunto de dados. $\mathrm{O}$ dado pode falar e revelar o não desejado, o latente, o inconsciente, sendo na busca deste dito não-dito que o conhecimento pode ser construído, avançando no que ainda não foi revelado pelas pesquisas realizadas até o momento, quando trata-se de entender a dinâmica organizacional.

\section{Algumas pesquisas empíricas}

A problemática da pesquisa empírica com o uso do referencial psicanalítico apresenta-se no próprio objeto de estudo, que deve ser responsável pelo acesso ao conteúdo e processos inconscientes que permeiam a organização. Tais objetos não constituem em si mesmo elementos do inconsciente, mas é através da investigação de sua natureza, relações e características, que o inconsciente pode se manifestar, sendo essa expressão interpretada a partir de um conjunto de dados sobre o objeto de estudo.

As pesquisas realizadas nos últimos anos com fundamentos nos conceitos psicanalíticos visam explicar a dinâmi- 
ca que envolve a relação simbólica indivíduo-trabalho-organização, consideradas na sua maior parte inconscientes e reveladoras de muitas dificuldades passadas pelas organizações e perturbações psíquicas provocadas nos trabalhadores.

Autores, como Baun (1987), Diamond (1993), Hirschhorn (1988), Kets de Vries e Miller (1984), Levenson (1983) e Mota e Freitas (2000), vêm estudando tais relações usando a perspectiva da Psicanálise para explicar as ações individuais como reações simbólicas a um contexto organizacional específico, sendo por isso, a estrutura organizacional influenciada e influenciadora das relações entre seus membros.

Para esses autores, guardadas as diferentes especificidades de cada modelo, fenômenos como ansiedade e sintomas neuróticos estão associados com a forma de os indivíduos experienciarem sua organização, bem como, a estrutura organizacional, caso neurótica, por exemplo, pode fazer com que seus empregados se comportem também de forma neurótica ou utilizem defesas diante dos conteúdos, muitas vezes dolorosos, que estas organizações resgatam da mais tenra infância, sendo reproduzidos no espaço de trabalho as suas primeiras relações objetais.

Na mesma direção, Fineman (1996), Finemam e Gabriel (1996), consideram a organização como um lugar onde as primeiras vivências, especialmente a ansiedade, são revividas, sendo a estrutura organizacional reflexo da apreensão e frustração dos seus membros, constituindo assim, uma arena de emoções, que tanto definem a estrutura organizacional, como são por ela definidas. Paz, Mendes e Gabriel (2000), estudando os vínculos psíquicos e o poder organizacional, também fundamentam suas idéias neste mesmo pressuposto, considerando que a forma pessoal como cada indivíduo experiencia a organização reflete simbolicamente as primeiras experiências infantis, que são recodificadas e construídas quando em contato com a realidade de trabalho.

Kaës (1991) oferece uma síntese destes aspectos ao considerar que a realidade psíquica é mobilizada, trabalhada e apoiada na dinâmica organizacional, e que as instituições estruturam e sustentam a identidade, sendo dessa forma um objeto para o indivíduo, passando a funcionar como um sistema de vínculos do qual o sujeito é parte interessada e parte integrante.

Segundo Gabriel (1999), são diversas as opções disponíveis no contexto organizacional que podem ser pesquisadas com o referencial psicanalítico, como estórias, análise de incidentes críticos, emoções, fantasias e metáforas.

As estórias podem ser vistas como manifestação de sintomas inconscientes. Quando se pede para que um trabalhador conte uma história que considera importante na sua organização, ele pode se projetar ou identificar-se com os personagens, assumindo papel de vítima, vilão, herói, transferindo emoções como medo, raiva, ódio ou amor que podem estar relacionados com a própria organização, com os colegas ou com as chefias.

Os incidentes críticos são carregados de simbolismos e emoções. Diferentes reações podem ser observadas em diferentes indivíduos para o mesmo fato, as lembranças são distintas, bem como a interpretação dos eventos.Tais incidentes podem ser investigados na direção de revelar as fantasias e estimular a associação livre de idéias para buscar a rede de significados latentes.

As emoções podem ser investigadas a partir do questionamento sobre os sentimentos dos indivíduos em determinado contexto ou quando submetidos a certas situações de trabalho. Tais emoções podem ser relacionadas a aspectos da história de vida do sujeito e a suas características de personalidade, sendo aprofundados elementos que associam experiências passadas com o vivido atualmente, bem como as estratégias de controle destas emoções e suas relações com os outros presentes no contexto de trabalho.

As fantasias podem ser investigadas em conjunto com as emoções por meio de questões como: Qual é o seu maior medo em relação ao trabalho ou a organização? Qual sua maior ambição? O que você faria se pudesse trocar de lugar com alguém? O que faria se ganhasse muito dinheiro ou se tornasse uma pessoa famosa? As questões podem ser tanto específicas ao contexto, como evasivas, para que haja espaço para projeção das fantasias.

A utilização de metáforas é relativamente recente, como nos estudos de Morgan (1991). Podem ser investigadas com questões que abarquem a percepção dos indivíduos da sua organização, tendo como referencial analogias com objetos, pessoas ou situações. O essencial para o pesquisador é a reação das pessoas à própria metáfora criada por ele ou dada, quais os sentimentos envolvidos que dirigem para uma interpretação dos conteúdos projetados na realidade organizacional, as fantasias, idealizações e identificações a fim de ser verificado o conteúdo inconsciente presente nesta situação.

Pesquisas realizadas por Mendes e colaboradores (Antogla, Magalhães \& Mendes, 2000; Diniz \& Mendes, 2000; Ferreira \& Mendes, 2001; Freitas \& Mendes, 2000; Mendes, 1995, 1996, 1999; Mendes \& Abrahão,1996; Mendes, Morrene et al., 2000; Mendes \& Linhares, 1996, Mendes, Martins, Ribeiro, Oliveira \& David, 2000; Silva \& Mendes, 2000) utilizam alguns conceitos da Psicanálise, diferenciando-se do que vem sendo proposto pela literatura ao enfocar objetos de estudos específicos e ao criar variações nas estratégias metodológicas mais comumente utilizadas.

Um dos objetos de estudos dessas pesquisas são as vivências de prazer e de sofrimento no trabalho. O prazersofrimento no trabalho vem sendo estudado pela psicodinâmica do trabalho desde os anos 80 , como um constructo 
dialético, que pressupõe ser o trabalho lugar de prazer e de sofrimento. Dejours $(1986,1993,1994,1999)$ tem utilizado conceitos da Psicanálise associados à teoria da sexualidade infantil, especificamente as pulsões e processos sublimatórios. Basicamente, faz uso de técnica de coleta de dados qualitativa, sendo realizadas entrevistas coletivas e tendo na fala a unidade de análise.

Quanto aos aspectos metodológicos, passou-se a utilizar, além de abordagem qualitativa, técnicas de coleta de dados quantitativas. Mendes, Morrone et al. (2000) validaram uma escala para medir o prazer-sofrimento - EIPST. Essa escala tem por objetivo uma descrição da situação dos trabalhadores em dado momento.

O uso da escala para medir o prazer-sofrimento fornece indicadores para ser aprofundado o estudo de uma dinâmica que extrapola o dado, que se configura num conjunto de relações, na maioria das vezes dialética, que permite a interpretação e o avanço do conhecimento ao confrontar o empírico com o teórico, sendo mais um elemento para orientar a interpretação.

Nessa perspectiva, para o estudo do prazer-sofrimento no trabalho, as técnicas qualitativas de coleta de dados foram mantidas, ora isoladamente em algumas pesquisas, ora para complementar as quantitativas. Pesquisas têm sido realizadas com entrevistas semi-estruturadas coletivas e individuais. Observamos que as entrevistas coletivas são mais adequadas para investigar as vivências de prazer-sofrimento na medida em que os sujeitos compartilham um sentimento sobre o trabalho e sentem-se apoiados no grupo que também vivencia os mesmos sentimentos, além de serem atingidos um maior número de participantes em menor tempo. Os procedimentos para condução dessas entrevistas são os mesmos já descritos na seção sobre aspectos metodológicos.

A técnica que vem sendo utilizada para análise destas entrevistas é a análise de conteúdo, e especificamente a análise de enunciação baseada em Bardin (1977). Consideramos importante a construção de categorias temáticas como indicadores para interpretação, que não é realizada apenas por meio destas categorias, mas tomando a entrevista como um texto construído por um sujeito com muito mais redes de significados do que as reveladas no conteúdo manifesto, importando assim, o sentido do discurso. Essa rede também é analisada por meio do conteúdo latente que tem expressão na linguagem manifesta por meio de certas particularidades.

A aplicação dessas estratégias metodológicas nas pesquisas sobre prazer-sofrimento tem alcançado resultados produtivos. A teoria tem se confirmado nos dados empíricos e os dados têm avançado os aspectos teóricos. Já foram realizadas 120 entrevistas ao longo de 4 anos e aplicada a escala em aproximadamente 1.500 participantes, o que está sen- do analisado no momento para subsidiar a construção de princípios teóricos para o constructo prazer-sofrimento.

Outra variável que vem sendo por nós estudada com o uso do referencial psicanalítico são os estilos de caráter nas organizações. Originalmente essa variável foi estudada como o vínculo psíquico com a organização. Partia-se do pressuposto que a organização enquanto entidade psicológica suscitava nos seus membros, por meio de uma relação simbólica, afetos e emoções de alguma forma relacionadas às suas primeiras experiências infantis. Metodologicamente, realizou-se entrevistas coletivas e a questão básica das entrevistas era "Se sua organização fosse uma pessoa, quem seria? Por quê? Como você se relaciona com ela?"

O contato mais aprofundado com modelos com uso de referencial psicanalítico nas organizações levou-nos a investigar o vínculo psíquico como os estilos de caráter. Esses estilos têm fundamento na teoria da sexualidade infantil, sendo cinco estilos de comportamento categorizados a partir das fases do desenvolvimento oral, anal e fálica: o estilo narcisista, o obsessivo, o coletivista, o individualista heróico e o individualista cívico. Considerando que nessas fases o sujeito se liga a objetos e objetivos de satisfação pulsional, o que define certas características de relacionamento com os outros e com mundo, passamos a considerar que o vinculo psíquico estabelecido com a organização expressa esses comportamentos, já vividos numa fase infantil.

O interesse pelo estudo dessa variável é identificar comportamentos compartilhados pela maioria dos membros da organização em determinada situação de trabalho. Não é uma variável individual, é uma variável que busca dar conta da relação simbólica indivíduo-trabalho-organização.

Metodologicamente, os estilos podem ser investigados por meio de entrevistas coletivas e individuais. As questões norteadoras são: como as pessoas se comportam nesta organização, quais as características de personalidade predominantes na maioria das pessoas e a metáfora da organização como uma pessoa. As verbalizações também são submetidas a análise de conteúdo, que oferece os indicadores para interpretação do estilo predominante, que não é medido diretamente ou de forma objetiva, mas integrado a um conjunto de dados, pistas e dicas que subsidiam a interpretação.

Os estilos também estão sendo medidos por meio de uma escala com cinco fatores, que compõem algumas características de cada um deles, servindo como mais um caminho para descrever, de um ponto de vista epidemiológico, a situação que envolve as relações simbólicas indivíduo-trabalho-organização.

O estudo dessas duas variáveis, prazer-sofrimento e estilos de caráter, está sendo realizado de forma integrada com o estudo de outras variáveis organizacionais como valores e poder nas organizações. O objetivo dessa integração 
é construir indicadores para o estudo da saúde organizacional. A tentativa é buscar problematizar a questão da saúde, considerando a organização como uma entidade psicológica, questionando os mecanismos psicopatológicos de funcionamento de tais organizações e suas estratégias de desenvolvimento da saúde.

Assim sendo, esses indicadores serão elaborados a partir de pesquisas empíricas com diversas organizações, sendo cada um deles resultado da interação entre as variáveis macro e micro organizacionais e da realidade das organizações a serem pesquisadas.

Essas pesquisas, apesar de recentes no campo da Psicologia Organizacional, vêm apresentando resultados que apontam na direção de que é possível ter acesso aos aspectos dinâmicos do contexto organizacional, que se integrados aos aspectos estruturais, processuais e funcionais, podem ampliar o entendimento do objeto de estudo da Psicologia Organizacional. Isso se daria, especialmente, se for mantido um diálogo constante entre as diferentes abordagens metodológicas na perspectiva de criar modelos teóricos, que contribuam para o que está posto como o modo natural de se fazer ciência. Nesse contexto, o referencial teórico da Psicanálise pode trazer aspectos como a dúvida, o não-dito e a interpretação para a pesquisa dos fenômenos organizacionais.

\section{Considerações finais}

A discussão dos aspectos epistemológicos e teóricos do uso do referencial psicanalítico nas pesquisas com organizações suscita mais indagações e reflexões do que conclusões. Por ser um campo relativamente recente, que não conta com um número suficiente de pesquisas empíricas, não é possível a elaboração de um conjunto de princípios que fundamentem todas as investigações da área. Ainda são muitas as especificidades teóricas e metodológicas que têm guiado a maioria das pesquisas, o que não invalida as contribuições que têm trazido para o fortalecimento deste campo de investigação.

Uma das maiores contribuições do uso do referencial psicanalítico é a problemática da dúvida, da interpretação e da forma como o conhecimento é construído, sem desconsiderar a importância dos conceitos específicos à Psicanálise, como o inconsciente, a teoria da sexualidade infantil, a teoria das pulsões e a transferência, para o entendimento das relações simbólicas indivíduo-trabalho-organização.

Apesar da dúvida fazer parte de qualquer modo de se fazer ciência, a dúvida sobre o que é dito e a busca pelo que se encontra por trás do aparentemente banal, constitui algo novo, que influencia no modo de escutar os fenômenos. Isso não significa criar sintomatologias paranóides. O conteúdo manifesto também tem seu lugar, sendo inclusive a partir de sua existência que o latente pode ser desvelado.
Essa dúvida se encontra na base do processo de interpretação, que não é realizada de forma isolada do contexto e sem direção própria, mas sim como um meio para construção do conhecimento, complementando os aspectos descritivos, funcionais e processuais com os aspectos analíticos, estruturais e dinâmicos para buscar entender a rede de significados mais amplos que envolvem o fenômeno.

Nessa perspectiva, se o psicanalista diferencia-se essencialmente dos psicólogos pelo modo de escutar (a escuta do inconsciente), o pesquisador das organizações que usa o referencial psicanalítico também se diferencia de outras abordagens no modo de escutar os fenômenos organizacionais. Ainda, diferencia-se na forma de olhar o fenômeno e analisar o dado. $\mathrm{O}$ dado expressa um significado que não se reduz ao dado em si, bem como, não são as estratégias metodológicas que criam diferencial epistemológico, o que importa é a interpretação do dado e a forma de construção do conhecimento.

Esse modo de escuta organizacional revela uma intersubjetividade que envolve a relação pesquisadorpesquisados, que faz parte do contexto de investigação, constituindo em algumas pesquisas com esse referencial, dado de análise e interpretação.

Finalmente, é na pesquisa empírica que se encontra o principal caminho para verificar as possibilidades de diálogo entre diferentes disciplinas. Os dados encontrados até o momento demonstram que a complementariedade, que não significa transposição conceitual ou aplicação direta de conceitos e implica manutenção das especificidades, é um caminho importante para realizar pesquisa nas organizações, tendo em vista que vêm permitindo uma explicação diferente para os fenômenos organizacionais, na qual a dúvida tem lugar na forma como se escuta o próprio o fenômeno.

\section{Referências}

Antogla, C. S. , Magalhães, C. V., \& Mendes, A M. (2000). Organização do trabalho e vivências de prazer-sofrimento: estudo exploratório com professoras alfabetizadoras [Resumo]. In Sociedade Brasileira de Psicologia (Org.), XXX Reunião Anual de Psicologia (p. 276). Brasília: SBP.

Assunção, M. A. (1977). A estruturação da entrevista psicológica. São Paulo: Atlas.

Bardin, L. (1977). Análise de conteúdo. Lisboa: Edições 70.

Baum, H. S. (1987). The invisible bureaucracy. New York: Oxford University Press.

Bleger, J. (1991). Temas de psicologia: entrevistas e grupos. São Paulo: Martins Fontes

Cassel, C., \& Symon, G. (1994). Qualitative research in work context. In C. Cassel \& G. Symon (Orgs.), Qualitative methods in organization research: a pratical guide (pp. 6-19). London: Sage.

Celes, L., \& Bucher, R. (1984). O sujeito: limite epistemológico da Psicanálise. Psicanálise, 4, 27-33. 
Dejours, C. (1987). A loucura do trabalho: estudo de psicopatologia do trabalho. São Paulo: Cortez.

Dejours, C. (1993). Travail: usure mental (vol. 1). Paris: Bayard.

Dejours, C. (1994). Psicodinâmica do trabalho: contribuições da escola dejouriana à análise da relação prazer, sofrimento e trabalho. São Paulo: Atlas.

Dejours, C. (1999). A banalização da injustiça social. Rio de Janeiro: FGV.

Diamond, M. (1993). The unconscious life of organizations. Interpreting organizational identity. London: Quorum.

Diniz, B. S. A., \& Mendes, A M (2000). Vivências de prazer e sofrimento no trabalho de chefes e não chefes: estudo exploratório numa empresa pública [Resumo]. In Sociedade Brasileira de Psicologia (Org.), $X X X$ Reunião Anual de Psicologia (p. 218). Brasília: SBP.

Ferreira, M. C., \& Mendes, A. M. (2001). "Só de pensar em vir trabalhar, já fico de mau-humor: atividade de atendimento ao público e prazersofrimento no trabalho". Estudos de Psicologia, 6, 97-108.

Freitas, L. C. O., \& Mendes, A. M. (2000). Estudo exploratório sobre estilos de caráter em profissionais de informática de uma empresa privada [Resumo]. In Sociedade Brasileira de Psicologia (Org), $X X X$ Reunião Anual de Psicologia (p. 218). Brasília: Autor.

Fineman, S. (1996). Emotion in organizations. London: Sage.

Fineman, S., \& Gabriel, Y. (1996). Experiencing organizations. London: Sage.

Freud, S. (1996). Sobre Psicanálise. In S. Freud, Obras completas (Vol. XII). Rio de Janeiro: Imago. (Texto original publicado em 1913).

Freud, S. (1996). História do movimento psicanalítico. In S. Freud, Obras completas. (Vol.XIV). Rio de Janeiro: Imago. (Texto original publicado em 1914).

Gabriel, Y. (1995). The unmanaged organization: stories, fantasies and subjectivity. Organization Studies, 16(3), 477-501.

Gabriel, Y. (1999). Organizations in depht. London: Sage.

Hirschhorn, L. (1988). The workplace within. Cambridge: MIT Press.

Kaës, R. (1991). A instituição e as instituições. São Paulo: Casa do Psicólogo.

Kets de Vries, M. F. R., \& Miller, D. (1984). The neurotic organization. São Francisco: Jossey-Bass.

Levenson, E. (1983). The ambiguity of change: an inquiry into the nature of psychoanalytic reality. New York. Basic Books.
Mannoni, M. (1981). A primeira entrevista em psicanálise. São Paulo: Campos.

Mendes, A. M. (1995). Os novos paradigmas de organização do trabalho: implicações para saúde mental do trabalhador. Revista Brasileira de Saúde Ocupacional, 85/86(1), 68-79.

Mendes, A M. (1996). Comportamento defensivo: uma estratégia para suportar o sofrimento no trabalho. Revista de Psicologia da UFC, 13(1/2), 27-32.

Mendes, A B. (1999). Valores e vivências de prazer-sofrimento no contexto organizacional. Tese de doutorado não-publicada, Universidade de Brasília, Brasília.

Mendes, A. M., \& Abrahão, J. I. (1996). A influência da organização do trabalho nas vivências de prazer-sofrimento do trabalhador: uma abordagem psicodinâmica. Revista Psicologia: Teoria e Pesquisa, 26(2), 179-184.

Mendes, A. M., \& Linhares, N. J. (1996). A prática do enfermeiro com pacientes da UTI: uma abordagem psicodinâmica. Revista Brasileira de Enfermagem, 42(2), 267-280.

Mendes, A. M., Martins, J. A., Ribeiro, E., Oliveira, M. S., \& David, G. R. (2000). Estilos de caráter nas organizações: construção e validação de um instrumento [Resumo]. In Sociedade Brasileira de Psicologia (Org.), XXX Reunião Anual de Psicologia (p. 221). Brasília: Autor.

Mendes, A. M., Morrone F. C., Watrin, B., Vieira G., Santos M., \& Brauer S. (2000). Escala de indicadores de prazer e sofrimento no trabalho (EIPST): Construção e validação [Resumo]. In Sociedade Brasileira de Psicologia (Org.), XXX Reunião Anual de Psicologia (p. 223). Brasília: SBP.

Morgan, G. (1991). Imágens de la organización. Mexico: Alfaomega.

Mota, P. C. F., \& Freitas, M. E. (Org.) (2000). Vida psíquica e organização. Rio de Janeiro: Vozes.

Paz, M. G. T., Mendes A. B., \& Gabriel, Y. (2000). Configurações de poder e estilos de caráter. Revista Trabalho e Organizações, 1(1), 141-169.

Silva, C. M. L., \& Mendes, A M. (2000). Estilos de caráter na natação: estudo exploratório [Resumo]. In Sociedade Brasileira de Psicologia (Org.), XXX Reunião Anual de Psicologia (p. 185). Brasília: SBP.

Ana Magnólia Bezerra Mendes, doutora em Psicologia Social e do Trabalho pela Universidade de Brasília, DF, é professora do Departamento de Psicologia Social e do Trabalho do Instituto de Psicologia da Universidade de Brasília. Endereço para correspondência: SQN 206 Bloco K 105, Asa Norte, 70862-010, Brasília, DF, Tel.: (61)274-6066. E-mail: anamag@yawl.com.br. 